\title{
SCIDOC
}

\author{
International Journal of Dentistry and Oral Science (IJDOS) \\ ISSN: 2377-8075
}

\section{Prevalence Of Ellis Class-I Restoration In Patients Above 16 Years Of Age - A Retrospective Study}

Research Article

\author{
Nivesh Krishna $\mathrm{R}^{1}$, Anjaneyulu $\mathrm{K}^{2 *}$, Arvind $\mathrm{S}^{3}$
}

${ }^{1}$ Saveetha Dental College and Hospitals, Saveetha Institute of Medical and Technical Sciences, Saveetha University, Chennai, India.

${ }^{2}$ Reader, Department of Conservative Dentistry, Saveetha Dental College and Hospitals, Saveetha Institute of Medical and Technical Sciences, Saveetha University, Chennai - 600077, India.

${ }^{3}$ Reader, Department of Orthodontics, Saveetha Dental College and Hospitals, Saveetha Institute Of Medical and Technical Science, Saveetha University, Chennai, India.

\section{Abstract}

Traumatic injuries of anterior teeth are often an ignored issue among children and young adults. In general, the adolescents who get treated for such traumatic injuries are those that occurred in their childhood and left untreated. Ellis I fractures involve the enamel layer. These injuries may elicit minor chipping with rough edges. The fractured teeth are usually nontender and without visible color change but have rough edges. The aim of this study is to elicit the prevalence of Ellis class-1 restorations in patients above 16 years of age. The data collected from the records were 86000 and they were screened for patients with Ellis class I restoration. Patients above 16 years of age who underwent Ellis class-I restoration from June 2019 to March 2020 were chosen and divided into three age groups. Group 1 includes patients between 16-25 years of age, group 2 includes patients between 26-35 years of age and group 3 includes 36-70 years of age. The most predominant age group with the maximum number of restorations was estimated statistically. From the study it can be estimated that among 130 patients who have undergone Ellis class-I restoration, the number of male patients were 77 and the number of female patients were 53 . Maximum patients who have undergone the treatment belong to group-1 (16-25 years) and the predominant gender was males with the highest frequency. To conclude, awareness of tooth fractures, its complications and need for treatment should be insisted among parents and adolescents. Oral screening to diagnose these fractures must be done at the earliest so that necessary steps can be taken to treat the condition and save the remaining tooth structures.

Keywords: Anterior Tooth; Bonding; Composite Resin; Dentin; Ellis Fractures; Enamel; Fragment Reattachment; Trauma.

\section{Introduction}

A fracture of the tooth is referred to as a break or a crack in the surface of the tooth. Enamel is the outermost layer of the tooth. It safeguards the vital part of the tooth which is the inner pulp of the tooth that contains nerves and blood vessels. Types of tooth fractures can be broadly classified into craze lines, fractured cusp, cracked tooth, split tooth,vertical root fracture. Shallow cracks that cause no pain and require no treatment are determined as craze lines.This type of fracture does not require any treatment [1]. Breakage involving the occlusal surface of the tooth involving one or more cusps refers to Fractured cusp. Cracked tooth is when the tooth cracks from the occlusal surface following down towards the root of the tooth. Cracks down through the root, separating a section of tooth is called a Split tooth. If the cracks begin in the root and move up toward the chewing surface, it is called Vertical root fractures. Not all tooth fractures cause any visible signs and symptoms. For instance, craze lines rarely cause problems since they involve only the enamel and rarely the dentin. But other fractures may expose the pulp to fluid, food, and bacteria in the mouth, thus causing irritation or infection to the pulp $[2,3]$.

Fracture of anterior teeth is the most frequent type of traumatic

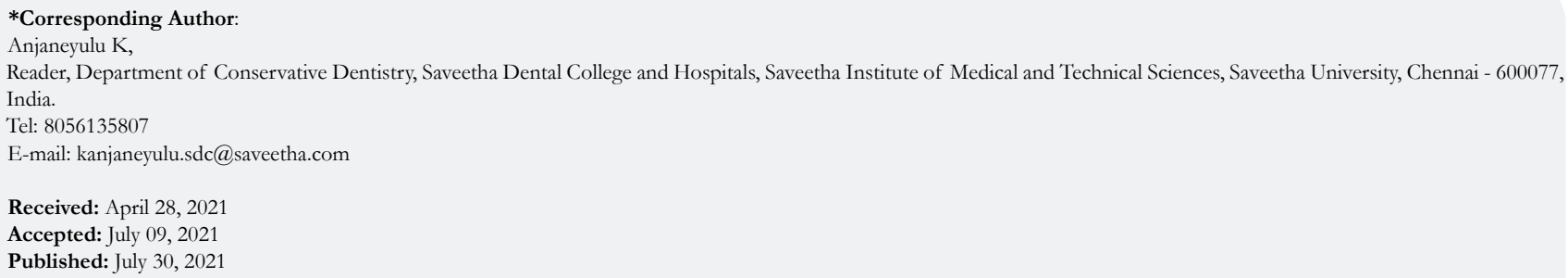

Citation: Nivesh Krishna R, Anjaneyulu K, Arvind S. Prevalence Of Ellis Class-I Restoration In Patients Above 16 Years Of Age - A Retrospective Study. Int J Dentistry Oral Sci. 2021;8(7):3563-3567. doi: http://dx.doi.org/10.19070/2377-8075-21000729

Copyright: Anjaneyulu $\mathbf{K}^{\circ}$ 2021. This is an open-access article distributed under the terms of the Creative Commons Attribution License, which permits unrestricted use, distribution and reproduction in any medium, provided the original author and source are credited. 
injury in the permanent dentition especially in children and adolescents i.e. patients below 25 years of age. It affects upto $45 \%$ of the young population. These fractures are considered to be uncomplicated if it involves only enamel and dentin and are complicated if it involves the dental pulp. According to Ellis and Davey classification, fracture of enamel and dentin falls under class I and class II respectively and fracture of dental pulp falls under class III type of fractures [4]. The management of coronal factors involves various factors such as extent of fracture, pattern of fracture, restorability of the tooth, presence or absence of fragment of the fractured tooth, aesthetics and occlusion. The choice of the restorative material should be made in such a way that it reproduces the esthetic and functional needs as much as the normal tooth structure $[5,6]$. In general, composite resin restorations are the most preferred type of restorative materials due to the fact that it replicates the exact tooth colour of the natural tooth but the mechanical strength of the material makes the durability questionable thus demanding the need for another mode of restoration with a better mechanical strength [7]. Fragment reattachment can be considered when the fracture line involves minimal or no dentinal involvement. Reattachment of the fractured fragment is considered to be the most effective treatment since it is highly conservative and involves the exact natural tooth structure [18]. Vertical root fractures occur when a bone or gum infection develops.

The diagnostic methods used for the diagnosis of such fractures involving the teeth includes the following. Dye staining is a method in which a solution is put on the tooth surface that aids in visualizing the fractured line for examination [9]. Transillumination includes passing a light through the tooth surface. Periodontal probing is a method in which tooth fractures are diagnosed by using special tools to look for the extent of crack. Bite test is a method of diagnosis in which the patient is asked to bite down on a stick to find the specific tooth that is fractured. The most predominantly practised method is the use of X-ray to look for fractures $[10,11]$.

Previously our team had conducted numerous clinical trials [1214], in vitro studies [15-17] and surveyed [18, 20] and reviewed [21-26] various aspects of endodontics and conservative dentistry over the past five years. Now we are focusing on retrospective studies, the idea for which has stemmed from the current interest in our community. The aim of the study is to estimate the prevalence of Ellis class-I restoration in patients above 16 years of age and discuss various treatment modalities.

\section{Materials And Methods}

\section{Sampling}

Non-probability sampling was collected from June 2019 to March 2020. The case sheets of the patients above 16 years of age who had reported to Saveetha Dental college for the treatment of gingival enlargement were reviewed. The external validity was good, as it is generalisable among patients of the same ethnic origins within the state and country.

\section{Ethical approval}

Ethical approval was obtained from the Institutional Ethical
Committee and scientific review board [SRB] of Saveetha Dental College. SDC/SIHEC/2020/DIAS/DATA/0619-0320

\section{Data Collection}

The data collected from june 2019 to march 2020 after screening 86000 records and study subjects were selected. Among the 86000 records, patients with Ellis class I restoration were chosen. The data was obtained by reviewing patients who reported to saveetha dental college. The data collected included parameters such as the patient's name, age, gender, diagnosis and the type of treatment done. The sample size was 130 patients. Patient data obtained was cross verified with treatment photographs. The data was collected and tabulated in the excel sheet and imported to spss software for statistical analysis.

\section{Statistical Analysis}

The data was imported to spss software by IBM version 25.0 for Windows OS in which the output variables were defined. The independent variables were age and gender whereas the dependent variables were the type of restoration done and the statistical mean value obtained. The statistical test used was the chi-square test to establish the results.

\section{Methodology}

The study patients above 16 years of age restored with Ellis classI were collected and divided into three groups based on their age. Group 1 includes patients between 16-25 years of age, group 2 includes patients between 26-35 years of age and group 3 includes 36-70 years of age. The most predominant age group and the most predominant gender with the maximum number of restorations was estimated statistically.

\section{Results}

From the study it can be estimated that among 130 patients who have undergone Ellis class-I restoration, the number of male patients were 77 and the number of female patients were 53 . The predominant gender was males with the highest frequency. Considering the age groups, group-1(16-25 years) includes 53 patients, group-2 (26-35 years) includes 45 patients and group-3 (36-70 years) includes 32 patients. The predominant age group with the highest prevalence of Ellis class-I restoration is 16-25 years i.e. group-1. From the statistical test, it can be estimated that figure-I indicates the distribution of study population based on age, wherein $41 \%$ of patients belonged to group- 1 with highest frequency and $25 \%$ of patients belonged to group-3 with a lowest frequency. Figure-II indicates the distribution of the study population based on gender wherein $59 \%$ of the patients were males with the highest frequency and $41 \%$ were females with the lowest frequency. A chi-square association test (chi-square - 8.305; df- $1 ; \mathrm{p}-0.016(\mathrm{p}<0.05)$ gives a statistically significant association between gender, age group and the presence of Ellis class-I restoration.

\section{Discussion}

Loss of tooth in the anterior region especially in adolescents leads to a loss of emotional issues causing lack of compliance and con- 
Figure 1: Pie chart showing the distribution of the patients across the three age groups.

Pink color denotes group 1 (16-25 years). Red denotes group 2 (26-35 years). Orange denotes group 3 (36-70 years)Among all the patients who underwent treatment for Ellis class- I, patients belonging to group 1 were found to be predominant $(40.77 \%)$, followed by group $2(34.62 \%)$ and group $3(24.62 \%)$.

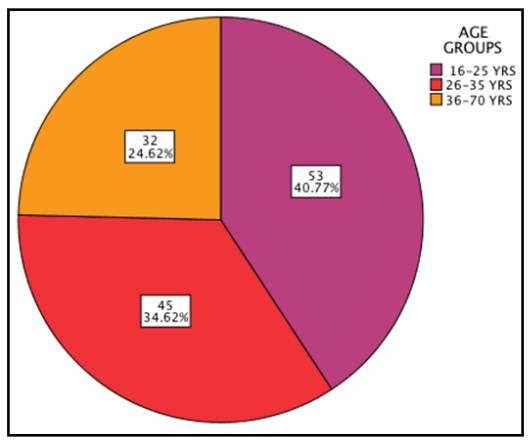

Figure 2: Pie chart showing the distribution of the patients based on gender.Males are denoted by yellow color and females are denoted by black color. From the study it can be estimated that among 130 patients who have undergone Ellis class-I restoration, the number of male patients were $77(59.23 \%)$ and the number of female patients were 53(40.77\%). The predominant gender was males with the highest frequency.

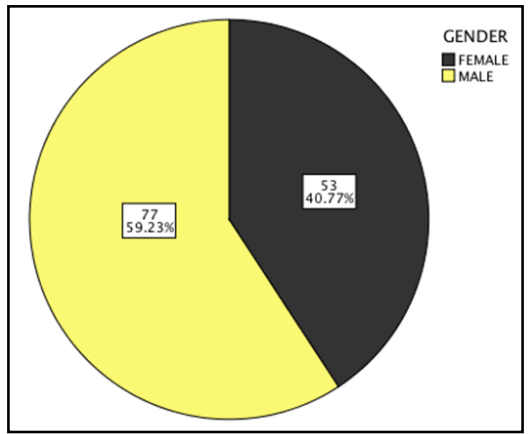

Figure 3: Bar graph showing the association between age group and gender prevalence of Ellis class-I restoration. $\mathrm{X}$ axis represents the age group and $\mathrm{Y}$ axis represents the number of patients. Males (yellow) had a higher number of Ellis class-I restoration than females (black) in group 1(16-25 years) and group 2(26-35 years) whereas in group 3 (36-70 years), female predominance was observed. In group 1 the number of males $(26.92 \%)$ were significantly higher than females(13.85\%). In group 2 the number of males $(23.08 \%)$ were significantly higher than females $(11.54 \%)$ whereas in group 3 the number of females $(15.38 \%)$ were significantly higher than males(9.23\%). (Chi-square value- 8.305 , p value- $0.01(\mathrm{p}<0.05)$; hence statistically significant)

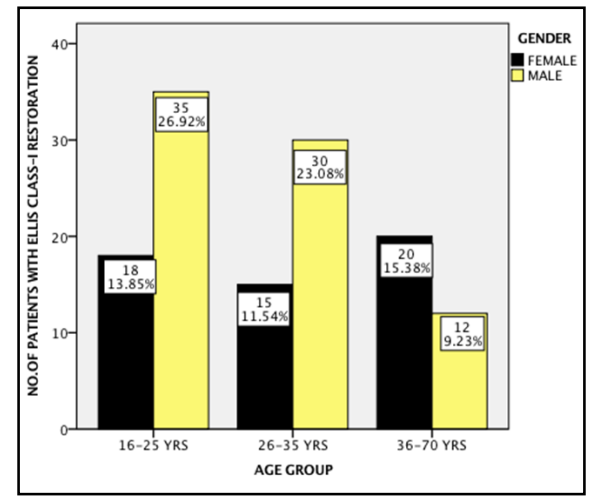

fidence. Restoration with composite resin is considered to be the first line of choice in treating a fractured anterior tooth. Composite resin restoration done with the help of acid etch technique is considered to be highly esthetic treatment which not only restores the aesthetics, form and function of the traumatised tooth but also restores other minor properties such as opalescence, fluorescence, translucency and surface gloss [27]. However it is evident that there is no synthetic restorative material that replicates the aesthetic characterization of colour stability of a natural tooth. Many studies have indicated that maximum patient satisfaction is obtained in fragmental reattachment when compared to any other mode of restoration. Composite restorations are found to be satisfactory in many studies both esthetically as well as functionally after an 18 month follow-up [28]. Studies have indicated that among 150 patients who had anterior permanent tooth fracture belonging to $15-25$ years, nearly $70 \%$ were males with a male female ratio of 2:1 indicating male predominance thus coinciding with our study.Considering the traumatic injuries wherein only the primary teeth were affected, male and female had almost an equal predominance but considering the permanent teeth, males had predominant number of such traumas and highest prevalence of restorations involving the anterior teeth $[29,30]$. 
Ellis class-I and II were the most prevalent types of traumas in children and adolescents. Children become more vulnerable to these types of traumatic injuries when exposed to falls, accidents etc. This sequelae of traumatic injuries affecting the primary tooth are also capable of affecting the permanent succedaneous tooth leading to malformation [31]. Various studies have suggested that Ellis class I and II fractures involving only enamel and dentin are common in $25-69 \%$ of cases and Ellis class III are common in $2-13 \%$ of children and young adults. Traumatic injuries affecting the adolescents requires greater attention because it involves their compliance towards aesthetics and thus enhances their confidence levels $[32,33]$. So restorative techniques are those that involve simplified treatment that not only improves aesthetics but also restores the form and function of the teeth. The restoration is also expected to have a long term success rate and a highest potential value.

A study by Sasikala et.al has indicated that concussion and subluxation are the most common types of traumatic injuries in children [34]. Studies by Siddharth Anand and Hamilton et al have indicated that $85 \%$ of Ellis class I and II are common with children below 20 years of age coinciding with our study $[35,36]$. A review by Gupta.B et.al, discussed on sports related maxillo- facial traumas in which more than $60 \%$ of individuals were affected with such fractures which were restored either by fragment reattachment or by composite resin restoration [37].

\section{Limitations}

The data may have discrepancies since it is limited to Ellis classI fracture confined to a specific geographic location. The study does not include age groups less than 16 years.

\section{Future scope}

The study gives a broad idea on Ellis classification of traumatic injuries and management of uncomplicated fractures in an effective way.

\section{Conclusion}

Awareness on tooth fractures, its complications, and the need for treatment should be insisted on among parents and adolescents. Oral screening to diagnose these fractures at the earliest must be done so that necessary steps can be taken to treat the condition and save the remaining tooth structures. Patients must be instructed on frequent reviews every 6 months to 1 year to check the quality of restoration and prevent restoration failure.

\section{Author Contributions}

First author [Nivesh Krishna R] performed analysis,interpretation and wrote the manuscript. Second author [Dr.Anjaneyulu] contributed to conception, data designs, analysis, interpretation and critically revised the manuscript. Third author [Dr.Arvind Sivakumar] participated in the study and revised the manuscript. All the three authors have discussed the results and contributed to the final manuscript.

\section{Acknowledgement}

I sincerely express my gratitude and acknowledgement to Dr.Anjaneyulu and Dr.Arvind Sivakumar and Dean and management for their support and also thank the Research and IT department of Saveetha dental college (SIMATS) for their affable assistance in analyzing the data.

\section{References}

[1]. Galea H. An investigation of dental injuries treated in an acute care general hospital. J. Am. Dent. Assoc. 1984 Sep 1;109(3):434-8.

[2]. Burton J, Pryke L, Rob M, Lawson JS. Traumatized anterior teeth amongst high school students in northern Sydney. Aust Dent J. 1985 Oct;30(5):3468.Pubmed PMID: 3868390.

[3]. Stockwell AJ. Incidence of dental trauma in the Western Australian school dental service. Community Dent. Oral Epidemiol. 1988 Oct;16(5):294-8.

[4]. Sheiham A. Impact of dental treatment on the incidence of dental caries in children and adults. Community Dent. Oral Epidemiol. 1997 Feb;25(1):104-12.

[5]. Zadik D. A survey of traumatized primary anterior teeth in Jerusalem preschool children. Community Dent Oral Epidemiol. 1976 Jul;4(4):149-51. Pubmed PMID: 1066201.

[6]. Kaushik S, Sharma R, Sharma V, Setya G, Assudani G, Arora A. Management of anterior tooth trauma: Two case reports. Endodontology. 2016 Jan 1;28(1):64.

[7]. Fornaini C, Rocca JP. Reattachment of a Fractured Anterior Tooth Segment With Pulp Exposure via Er:YAG and Nd:YAG Lasers. Trauma Mon. 2015 Nov;20(4):e21470.Pubmed PMID: 26839857.

[8]. Hegde MN, Sajnani AR. Prevalence of permanent anterior tooth fracture due to trauma in South Indian population. Eur J Gen Dent. 2015 May $1 ; 4(2): 87$

[9]. Rai B, Kaur J. Cement and Tooth Colored Materials. Fundamentals of Operative Dentistry. 2010:1.

[10]. Parma-Benfenati S, Roncati M, Galletti P, Tinti C. Peri-implantitis Treatment with a Regenerative Approach: Clinical Outcomes on Reentry. Int. J. Periodontics Restor. Dent. 2017;35:625-36.

[11]. Zavan B, Bressan E, editors. Dental stem cells: regenerative potential. Humana Press; 2016 Jul 25.

[12]. Ramamoorthi S, Nivedhitha MS, Divyanand MJ. Comparative evaluation of postoperative pain after using endodontic needle and EndoActivator during root canal irrigation: A randomised controlled trial. Aust Endod J. 2015 Aug;41(2):78-87.Pubmed PMID: 25195661.

[13]. Hussainy SN, Nasim I, Thomas T, Ranjan M. Clinical performance of resinmodified glass ionomer cement, flowable composite, and polyacid-modified resin composite in noncarious cervical lesions: One-year follow-up. J Conserv Dent. 2018 Sep-Oct;21(5):510-515.Pubmed PMID: 30294112.

[14]. Janani K, Palanivelu A, Sandhya R. Diagnostic accuracy of dental pulse oximeter with customized sensor holder, thermal test and electric pulp test for the evaluation of pulp vitality: an in vivo study. Braz. Dent. Sci. 2020 Jan 31;23(1):8.

[15]. Ramanathan S, Solete P. Cone-beam Computed Tomography Evaluation of Root Canal Preparation using Various Rotary Instruments: An in vitro Study. J Contemp Dent Pract. 2015 Nov 1;16(11):869-72.

[16]. Nandakumar M, Nasim I. Comparative evaluation of grape seed and cranberry extracts in preventing enamel erosion: An optical emission spectrometric analysis. J Conserv Dent. 2018 Sep-Oct;21(5):516-520.Pubmed PMID: 30294113.

[17]. Teja KV, Ramesh S, Priya V. Regulation of matrix metalloproteinase-3 gene expression in inflammation: A molecular study. J. Conserv. Dent. 2018 Nov;21(6):592.

[18]. Rajendran R, Kunjusankaran RN, Sandhya R, Anilkumar A, Santhosh R Patil SR. Comparative evaluation of remineralizing potential of a paste containing bioactive glass and a topical cream containing casein phosphopeptide-amorphous calcium phosphate: An in vitro study. Pesqui Bras Odontopediatria Clin Integr. 2019 Oct 10;19:1-10.

[19]. Manohar MP, Sharma S. A survey of the knowledge, attitude, and awareness about the principal choice of intracanal medicaments among the general dental practitioners and nonendodontic specialists. Indian J Dent Res. 2018 Nov-Dec;29(6):716-720.Pubmed PMID: 30588997.

[20]. Jose J, Subbaiyan H. Different treatment modalities followed by dental practitioners for Ellis class 2 fracture-A questionnaire-based survey. Open Dent. J. 2020 Feb 18;14(1):59-65.

[21]. Teja KV, Ramesh S. Shape optimal and clean more. Saudi Endod. J. 2019 Sep 1;9(3):235. 
[22]. Noor SS. Chlorhexidine: Its properties and effects. Res J Pharm Technol. 2016;9(10):1755-60.

[23]. Kumar D, Antony S. Calcified canal and negotiation-A review. Res J Pharm Technol. 2018;11(8):3727-30.

[24]. Ravinthar K. Recent advancements in laminates and veneers in dentistry. Res J Pharm Technol. 2018;11(2):785-7.

[25]. Rajakeerthi R, Nivedhitha MS. Use of cone beam computed tomography to identify the morphology of maxillary and mandibular premolars in Chennai population. Braz. Dent. Sci. 2019 Jan 31;22(1):55-62.

[26]. Siddique R, Sureshbabu NM, Somasundaram J, Jacob B, Selvam D. Qualitative and quantitative analysis of precipitate formation following interaction of chlorhexidine with sodium hypochlorite, neem, and tulsi. J Conserv Dent. 2019 Jan-Feb;22(1):40-47.Pubmed PMID: 30820081.

[27]. Calişkan MK. Surgical extrusion of a cervically root-fractured tooth after apexification treatment. J Endod. 1999 Jul;25(7):509-13.Pubmed PMID: 10687519.

[28]. Olsburgh S, Jacoby T, Krejci I. Crown fractures in the permanent dentition: pulpal and restorative considerations. Dent Traumatol. 2002 Jun;18(3):10315.Pubmed PMID: 12110103

[29]. Trushkowsky RD. Esthetic, biologic and restorative considerations in coronal segment reattachment for a fractured tooth: a clinical report. J Prosthet Dent. 1998 Feb;79(2):115-9.Pubmed PMID: 9513093.

[30]. Meiers JC, Freilich MA. Use of a prefabricated fiber-reinforced composite resin framework to provide a provisional fixed partial denture over an integrating implant: a clinical report. J Prosthet Dent. 2006 Jan;95(1):14-8. Pubmed PMID: 16399269.

[31]. CHRISTENSEN GJ. Posts: necessary or unnecessary?. J Am Dent Assoc. 1996 Oct 1;127(10):1522-6

[32]. Trabert KC, Caputo AA, Abou-Rass M. Tooth fracturel3-A comparison of endodontic and restorative treatments. J. Endod. 1978 Nov 1;4(11):341-5.

[33]. Samadzadeh A, Kugel G, Hurley E, Aboushala A. Fracture strengths of provisional restorations reinforced with plasma-treated woven polyethylene fiber. J Prosthet Dent. 1997 Nov; 78(5):447-50.Pubmed PMID: 9399185.

[34]. Pagadala S, Tadikonda DC. An overview of classification of dental trauma. Int. Arch. Integr. Med.2015;2(9).

[35]. Anand S, Hegde DY, Yeluri R, Masih U, Yadav P, Kumar S. Comprehensive management of complicated crown fracture in a 10 -year-old child. Int. J. Pedod. Rehabil. 2017 Jan 1;2(1):46.

[36]. Hamilton FA, Hill FJ, Holloway PJ. An investigation of dento-alveolar trau$\mathrm{ma}$ and its treatment in an adolescent population. Part 1: The prevalence and incidence of injuries and the extent and adequacy of treatment received. $\mathrm{Br}$ Dent J. 1997 Feb 8;182(3):91-5.Pubmed PMID: 9055474.

[37]. Gupta R, Agrawal V, Gupta S, Gupta S. Unusual foreign body in oropharynx: a case report. Int J Res Med Sci. 2015;3:800. 